\title{
GLOBALIZATION, GROWTH AND INEQUALITY: TESTING CAUSALITY AND ASYMMETRIES
}

\author{
Juliet Abakumova ${ }^{1, a}$ and Olena Primierova ${ }^{2, b, *}$ \\ ${ }^{1}$ Department of Analytical Economics and Econometrics, Belarusian state university, Minsk, Belarus \\ ${ }^{2}$ Department of Finance, National university of Kyiv-Mohyla academy, Kyiv, Ukraine \\ aabakumovajg@bsu.by, ${ }^{\mathrm{b}}$ o.primierova@ukma.edu.ua \\ "Corresponding author
}

Cite as: Abakumova, J., Primierova, O. (2018). Globalization, growth and inequality: testing causality and asymmetries. Ekonomicko-manazerske spektrum, 12(2), 83-95.

Available at: dx.doi.org/10.26552/ems.2018.2.83-95

\begin{abstract}
Interest about income distribution and inequality have substantially grown in recent years. First of all, it can be explained by the increase in inequality as a major threat for the stability of society and economy, that often try to associate with the consequences of the globalization process and slowdown in the global economy. Hence the need for research and constructive discussions on inequality, and its causes. As hypotheses, as a rule, statements are tested: economic growth leads first to an increase, and then to a decrease in inequality; high income differentiation stimulates higher growth rates; the processes of globalization contribute to reducing inequalities in the world. The aim of the empirical part of submitted research is to analyse the relationships between income inequality and economic growth, income inequality and globalisation. The choice of methods to confirm the assumptions was determined by the properties of the long-term relationship between time series of indicators. Study has employed a single-country regression to investigate the existence of the Kuznets curve hypothesis for the Ukraine economy over the period 1995-2016. The bounds testing (ARDL) approach to cointegration is applied to examine the long-run relationship between income inequality and economic growth. The results, when regressing Gini index and GDP per capita based on purchasing power parity, confirm the presence of hidden cointegration. The Granger causality test was applied in order to test the existence of a causal relationship between the degree of globalization and income inequality. For case of Ukraine there is relationship between globalization process and inequality in the long run. Also the causality test revealed some cyclicality, in other words, there is the interchange of one-way direction of causality.
\end{abstract}

Keywords: globalization, income inequality, economic growth, hidden cointegration, bounds testing approach

JEL Classification: C01, C12, D33, F60

\section{Introduction}

One of the most important goals of the economic policy of any state is to ensure sustainable economic growth, which is understood as the growth of welfare, as well as an increase in the national wealth of the country. When solving problems and developing mechanisms of measures to achieve this goal more and more attention is paid to the problems of inequality and poverty.

Achieving sustainable economic growth is a key element of the economic strategy, a common reference point for the country's economic policies of most states. Indeed, economic 
growth has always been considered an indicator of the effectiveness of the economic system and remains an important condition for its development. In the narrow sense, it implies a positive dynamics of changes in the absolute and relative volume of real GDP. And in the broader - it is associated with the formation of economic and social conditions, in order to ensure changes in the level and quality of life, overcome poverty and reduce economic inequality in the country.

Inequality indicators, along with national income per capita, are now included in the formula for calculating the human development index (HDI), which is an integrated indicator that characterizes the living standards of different countries and regions. In general, in recent years, the relevance of empirical research devoted to the study of the impact on economic growth of factors associated with the social, which is not only limited to differences in income, and even gender inequality, has increased.

Currently, among the problems actively discussed by researchers regarding inequality - its relationship with the productivity of the economy or with economic growth. Researches of inequality represent both the development of theoretical concepts and economic and mathematical models, and an empirical analysis of statistical dependencies between these indicators in the form of spatial data and in dynamics. Recently, the greatest attention of researchers is attracted by the issues of the connection of inequality with the productivity of the economy or with economic growth. The focus is made on the development of theoretical and methodological foundations of the study of inequality, the development of appropriate economic and mathematical models, and an empirical analysis of statistical dependencies between these indicators in the form of spatial data and in dynamics. However, numerous scientific works aimed at studying the mutual influence of economic growth and inequality in the distribution of income, and could not give an unambiguous answer about the nature of this influence. Some theorists suggest that economic growth affects the level of income inequality, while others - inequality affects the rates of development. There are a number of theories in which both variables are positively correlated, in other theories a negative relationship is proved. As a conclusion, two statements are most often used: (i) economic growth leads to increased first, and then to reduce inequalities; (ii) high income differentiation stimulates higher growth rates. At the end of the last century, the economic data provided enough examples of that says about the limitations of these concepts: economic growth was accompanied by both strengthening and weakening of inequality, and high growth rates were achieved with initially low income differentiation. For example, China's economy is characterized not only by high rates of economic growth, but also by a high level of income inequality. On the other hand, a high level of differentiation of the population by income can lead to social and political conflicts, thereby impeding economic growth. There are a number of channels through which inequality can have a negative impact on economic growth: imperfect credit market, the threat of socio-political stability, limiting investment in human capital, and so on. It is also worth emphasizing that in the framework of the research, developed countries were most often considered. Among the post-Soviet states, the most of researches was conducted for the Russian Federation, Belarus and Kazakhstan, while the situation in Ukraine is still not until the end studied. In the current study, the authors attempted to confirm or disprove the existence of the relationship between economic growth and income inequality using econometric methods.

\subsection{The Impact of Economic Growth on Income Inequality}

This relationship was first investigated by the American economist Kuznets (1955), which showed that economic growth first leads to an increase in inequality, and then to its decreasing. Over the years, the U-shaped Kuznets curve has been subjected to a large number of tests, which 
resulted in both confirmation of the conclusions obtained by S. Kuznets and their refutation. For example, Paukert (1973) and Ahluwalia (1976) found evidence of the existence of an inverted Kuznets curve for developing countries. However, Oshima (1962) studies have shown that there is a relationship of such a form, however, but it must be taken into account that generalizations concerning inter-country models need to be made taking into account the huge historical, physical, regional, political, racial and religious differences.

Deininger \& Squire (1998) tried to more fully test the hypothesis Kuznets. First, they used a more qualitative data than previous researchers. Secondly, for different countries, comparable data were used for several moments of time. The result for their sample was that no evidence was found for an inverted U-model for individual countries. In most cases, it has not been possible to find any significant changes in income distribution over the past decades. It was then further explored the question of whether there is a link between rapid growth and growing inequality, and again there was found no systematic evidence in favor of such laws.

These results are consistent with earlier research Ravallion \& Chen (1996), who also did not find a systematic relationship between growth rate and inequality. This indicated that the economic policy aimed at rapid economic growth, is a vital element in poverty reduction strategies. However, it is obvious that the impact of growth on the poor depends on how the benefits are distributed among the population. Therefore, Deininger \& Squire (1998), studying economic growth and the share of income of various groups, investigated how the initial inequality, and also how the change in inequality affect poverty. It was found that the poor (up to 20 percent of the poorest) are the most affected by the economic downturn, as well as benefit from the measures that stimulate economic growth than the richest 20 percent. In addition, Ravallion \& Chen (1997), analyzing data from household surveys in 67 developing countries over the period 1981-1994, also found that empirically there is a very strong correlation between the growth of per capita income and poverty reduction. It is worth noting that even if there is a strong link between GDP growth and poverty reduction, it may turn out that countries with initially serious income inequalities may be less successful in reducing poverty. The same conclusion was reached by Kean \& Prasad (2001) on the results of a study of 14 countries with transition economies. Also they showed that similar results hold if one examines alternative inequality measures such as quantile ratios, quantile shares, or kernel density estimates of the income distribution.

Some publications contain the analysis of considered relationships at a regional level. In Michalek \& Vybostok (2018) for the analysis of interactions between growth and distribution in correlation to poverty reduction in Slovakia, the Bourguignon model (the Poverty-GrowthInequality triangle) and the growth incidence curve (GIC) were used. Authors was found that economic growth positively influences income inequalities as well as decreases the share of population under the poverty threshold in regions. The results also demonstrate that economically strong regions dealt better with the crisis and its consequences.

\subsection{The Impact of Income Inequality on Economic Growth}

For the first time the idea of the existence of the impact of inequality in the distribution of income on economic growth was formulated in the mid-20th century by Kaldor (1956). Also mention should be made of the publications of Barro (2000) and Figini (1999). Barro identified four key channels in explaining the impact of inequality on economic growth: imperfect credit markets, political process, socio-economic tensions, and differences in saving rates. Figini, in turn, considered the inequality in the distribution of income at the household level, as well as its demographic and socio-psychological consequences. 
While some models, such as the Harrod-Domar model, predicted that greater inequality would lead to higher growth rates, in the 1990s an opposite phenomenon was observed: greater inequality led to a lower level of the total growth. Therefore, some empirical evidence in both industrialized and less developed countries, as a rule, confirms the negative impact of inequality on growth.

Such a link was found in cross-country data. (Persson \& Tabellini, 1994; Alesina \& Rodrik, 1994) The mentioned authors interpreted the results in the context of the political economy, and their argument was that when the inequality is high level, the median voter will seek high (distorting) taxes on the wealthier, which will have a deterrent effect on savings, which in turn will lead to reduction of economic growth. However, further verifications of this proposal have questioned its validity, and evidence of distracting effects of taxation is still rather weak.

Another possible way from inequality to growth is through social conflicts, when inequality leads to increased political instability, which leads to a decrease in efficiency and investment level, and then to a recession. (Alesina \& Perotti, 1996) It was also argued that instability reduces the ability of governments to respond to external shocks. (Rodrik, 1999). Deininger and Squire (1998) tested the link between inequality and growth, but found no consistent relationship between the level of initial income inequality and growth. Nevertheless, they found that high income inequality in poor countries has a significant negative impact on future growth. This can be explained by the fact that for poor countries it may not be possible to finance the training or make other investments. The lack of assets can also reduce opportunities for participation in the political process and, consequently, also reduce access to resources. As soon as countries become rich enough, this link between high inequality and low growth seems to disappear. The authors of another study found that low income inequality in East Asia contributed to rapid economic growth. In addition, policies aimed at reducing poverty and income inequality, such as improving basic education and measures that increase the demand for labour, also stimulated economic growth. (Birdsall et al., 1995) However, the discussion about how the empirical relationship between growth and inequality looks is not yet complete.

Forbes (2000) conducted a study of panel data using a method that allows for the consideration of the fixed effects for countries to assess how the inequality in a country affects its growth. Then, contrary to previous studies, she found a stable and significant positive relationship between income inequality and growth. It is also interesting to note that Forbes argues that the problem in the papers of authors who previously received a negative impact of inequality on economic growth could be that the authors used non-comparable data on inequality in cross-section samples (since data on some countries had to be collected from "national sources"), and also that the data was of poor quality. Secondly, the author argues that when using spatial sampling, the problem of missing variables arises, since in a number of works with the addition of dummy-variables for regions, the significance of the Gini coefficient was lost, therefore, it is necessary to use panel data, with which the problem of missing essential variables is reduced by taking into account variables that do not change with time. It is also interesting to note the result obtained in the paper by Sonin (2000). The main aim of the work was to evaluate how affects property rights protection on economic growth in Russian regions over the period 1994-1997. According to the model proposed by the author, the direct impact of inequality on economic growth should be negative, because in the case of low protection of property rights, economic agents tend to spend resources on consumption, rather than on investment, which leads to slower economic growth. However, this conclusion is wrong, if we talk about the indirect impact of inequality on growth. Indirect impact must be positive, since the greater the inequality, the poorer voters, the more demand for the protection of property 
rights. Moreover, the poorer the "losers" from redistribution, the less attractive is the redistribution for the "winners".

The research by Madsen et al. (2018) examines the four possible channels through which inequality transmits to growth: savings, investment, education, and knowledge production. The authors also have used a panel data in the study: statistics for 21 OECD countries over the period 1870-2011. The results show that inequality hampers growth in financially underdeveloped economies but has little effect on growth at advanced levels of financial development. In conclusion it is recognized that the consequences of inequality on growth remain unclear and the empirical evidence remains mixed and inconclusive.

Thus the analysis of papers on this topic showed that in some of them noted the negative effect of inequality in the distribution of income on economic growth, while other authors conclude that there is a positive impact of inequality on economic growth, and still others prove the existence of a complex, non-linear relationship between income inequality and economic growth. Thus, it is possible to divide all approaches to the definition of the above influence on three groups:

(i) Presence of positive influence. From the economic point of view, this is justified by the fact that the wealthy strata of the population have a higher propensity to save, which increases the investment potential of these strata and the economy as a whole. In addition, the differentiation of wages can stimulate the growth of labour productivity of employees (increased competition).

(ii) The presence of negative influence. This is due to the fact that low- and middle-income households spend the majority of their income on consumption (in particular, on food products for low-income families). And since consumption is the basis of aggregate demand in the economy, reducing the inequality in income distribution, or, more precisely, increasing the incomes of these population groups, can stimulate economic growth. In addition, it can be noted that, as a rule, households with a high level of earnings prefer high-quality and exclusive goods, while the middle class is focused on acquiring mass-produced goods (where an increase in labour productivity is possible). This means that a reduction in income inequality can have a positive impact on economic growth, because this increases the demand for products with characteristics that are more conducive to growth. In addition, with the increase in inequality, the level of redistribution in the economy increases. This, in conditions of undeveloped credit markets, hampers the formation and accumulation of human capital and the implementation of investment projects. The redistribution policy (through, for example, taxation of income from holding a capital), in turn, limits growth, reduces the level of private investment, increasing disproportions in the economy and slowing the pace of economic growth. Inequality also increases social tension: social unrest, rising crime, raising the level of uncertainty for investors, which in turn does not contribute to economic growth.

(iii) To date, there is not enough information to make an unambiguous conclusion about the impact of income inequality on economic growth. The authors, referred to this group, however, do not deny the existence of this influence. It is also worth noting that more often a conclusion is drawn about the need to reduce inequalities in income distribution.

It can be concluded that the results greatly depend on the quality of the data of the inequality indicators, as different countries may vary methodology for measuring income, so to verify the reliability of the results should be used several measures of inequality. Moreover, the factors that may have a negative impact on economic growth, such as the imperfection of the financial market, will be stronger in developing countries. Hence, it is necessary to select more "similar" countries or, for example, to divide the sample into developed and developing countries. 
Globalization, Growth and Inequality:

Testing Causality and Asymmetries

Authors: Juliet Abakumova, Olena Primierova

\subsection{The Income Inequality and Globalization}

According to economic theory globalization would lead into enhanced economic growth which in turn has often been considered as an antipoverty measure. Therefore, we can expect a positive impact of globalization on income inequality through the economic growth. At the same time can't be denied that the trade openness, foreign direct investment and foreign remittances may contribute in reducing income inequality. But if we're discussing about the ambiguity of conclusions regarding the relationship between economic growth and income inequality, then these results can be extended to the case of the influence of globalization on inequality. Some of studies have suggested that globalization does not confer any discernible effect on economic inequality or, if any, confers some negative effect. Thus there are differing evidences on the impact of globalization on income inequality.

In publications in recent years began to come to a relative consensus on the impact of globalization, having considered the problem in two directions: analysis 'between' and analysis 'within'. The impact of globalization between countries lead to higher income growth in developed countries and widening income inequality between less developed countries. The remaining divergent opinions concern on the effect of globalization within countries, in respect to income inequality (poverty) and economic growth too. In particular, one can talk about the asymmetry of the effect: thus, Wei \& Wu (2001) found, that globalization did not contribute to economic inequality within countries but lack of globalization increased inequality within many countries. Bourguignon (2018) formulates, that changes in inequality appear to be very countryspecific. There may be common channels for the impact of globalization on inequality, but, for example, with asymmetry of effect. But at the same time, in various countries possibly there are another their different ways by which globalization may have affected income inequality.

So Adams (2007) examined the impact of globalization on income inequality for a crosssectional data of 62 developing countries over a period of seventeen years. The results of the study indicate that globalization explains only $15 \%$ of the variance in income inequality. These findings suggest that globalization has both positive and negative effects for inequality.

Zhou et al. (2011) investigated the impact of globalization on income inequality distribution in 60 developed, transitional and developing countries in 2000. The study showed that globalization can either mitigate or worsen the income inequality.

In Alderson and Nielsen (2002) suggesting that globalization is helpful to explain increasing economic inequality within countries. They investigated the relationship of globalization to the 'great U-turn' in 16 OECD countries. They find that in the period between 1967 and 1992 ten of these countries experienced rising inequality, or a period of inequality decline followed by rising inequality. Then Alderson and Nielsen supposed that the studied experience of some industrial societies suggests radical reversal in regard to Kuznets curve, where inequality declining with development.

While most often being discussed such effect of globalization as decreasing inequality between countries, in Bourguignon (2016) and Milanovic (2016), the present period of globalization is essentially seen not only as the cause of decreasing of inequality between countries but, in the same time, of rising of inequality within countries.

\section{Methodology}

To analyse the relationship between economic growth and income inequality were considered such factors as the Gini index and the gross domestic product (at purchasing power parity) per capita. The study used data from the World Bank for Ukraine for the period 19952016. Alternative indicators of income inequality also considered the decile ratio and the 
quintile ratio. In general, the results obtained not dependent on the choice of indicators of income inequality.

Additionally, considered an indicator such as the globalization index KOF. KOF globalization index was created by Axel Dreher (Swiss Economic Institute) in 2002. It includes economic, social and political dimension of globalization. Globalization generally has no direct significant impact on the economic growth. Some researchers examining the links with economic, social and political dimensions of globalization separately, it was found that considerable political engagements have negative effect on growth. And economic and social globalization effects on countries economic growth depend on a country's economic situation: i) economic integration does not have statistically significant impact on relatively less developed countries and has positive effect in the group of more developed countries; ii) social globalization has statistically significant impact on relatively less developed countries and has negative effect in the group of more developed countries. (Butkus et al., 2017). In the current study, the authors were to a greater extent interested in the issue of its mutual influence with the income inequality indicator.

For this research authors have chosen two hypotheses. These hypotheses are the following: (I) Existence of the cointegration between income inequality (variable GINI) and gross domestic product (variable GDP); (II) Detecting the presence and absence of causal relationships between income inequality (variable GINI) and globalization (variable KOF).

To further analyse the relationship between the time series of indicator dynamics, an approach based on the search for hidden cointegration was used. Hidden cointegration is a case of non-linear cointegration, which determines the presence of cointegration between the components of time series, but not between their levels. As an example, we can cite cases where time series have the same behaviour only for impulses (shocks) of a particular type. In such cases, in spite of the lack of cointegration between the initial variables, separately taken positive and negative components of the original series can be cointegrated. In our study, as a time series component of GINI and GDP were taken deviation from the average value of each series. To identify hidden cointegration, an autoregressive distributed lags (ARDL) model was considered, in which the components of the original series are included as some variables. Four models have been evaluated to verify the cointegration between components, testing the hypothesis of absence cointegration was carried out using bounds test (Granger \& Yoon, 2002):

$$
\begin{aligned}
& d y_{t}=a_{0}+\sum_{i=1}^{m} a_{1 i} d y_{t-i}+\sum_{i=1}^{m} a_{2 i} d x_{t-i}+\beta_{1} y_{t-1}+\beta_{2} x_{t-1}+\varepsilon_{t}, \\
& H_{0}: \beta_{1}=\beta_{2}=0 .
\end{aligned}
$$

The hypothesis of the absence of cointegration is verified using F-statistics and critical points $\mathrm{I}(0)$ and $\mathrm{I}(1)$. If the value of F-statistics is higher than the critical point $\mathrm{I}(1)$, the hypothesis of the absence of cointegration is rejected. In the case where the value of F-statistics is lower I(0) the hypothesis $H_{0}$ is accepted. If the value of the F-statistic lies between the critical points $\mathrm{I}(0)$ и I(1), then we cannot make a conclusion about the cointegration (uncertainty zone). Selection of the optimal lag was based on Akaike information criterion (AIC).

Granger Causality test is used to confirm the existence of the causal relationship between GINI and KOF within testing the hypothesis II. The Granger causality test, initially proposed by Engle \& Granger (1987) and Granger (1988), is based on using the following Vector Autoregression (VAR) mechanism: 


$$
\begin{aligned}
& K O F_{t}=\lambda_{0}+\sum_{i=1}^{k} \lambda_{1 i} \operatorname{GINI}_{-i}+\sum_{i=1}^{k} \lambda_{2 i} K O F_{t-i}+\varepsilon_{2 t} . \\
& G I N I=\theta_{0}+\sum_{i=1}^{k} \theta_{1 i} \operatorname{GINI}_{-i}+\sum_{i=1}^{k} \theta_{2 i} K^{k} O F_{t-i}+\varepsilon_{1 t},
\end{aligned}
$$

For checking whether GINI Granger Causes KOF Eq. 2 can be used. Here the null hypothesis $\mathrm{H}_{0}: \lambda_{1 i}=0$, which states that there is no causal relationship between GINI and KOF against the alternative $\mathrm{H}_{1}$ : at least one of $\lambda_{1 i} \neq 0$ which states that there is causal relationship between the two variables and GINI does Granger Cause KOF. Similarly, from Eq. 3 the null hypothesis, $\mathrm{H}_{0}: \theta_{2 \mathrm{i}}=0$, states that there is no causal relationship between KOF and GINI against the alternative, $\mathrm{H}_{1}$ : at least one of $\theta_{2 i} \neq 0$, stating that KOF does Granger Cause GINI.

\section{Results}

The Fig.1 represents the dynamics of variable: real GDP (annual growth, \%), Gini index and KOF globalization index of Ukraine from 1998 to 2016. Not so difficult to see, that the figure shows a negative relationship between KOF and GINI (for example, highlighting the periods of KOF growth, pay attention that the Gini index in these periods more often was characterized by a tendency to decrease). Thus, a preliminary analysis confirms the existence of a relationship and we can expect an alleviation of the income differentiation in the society if the coefficient KOF rising, i.e., the scale of Ukraine's integration into global space will increase.

Figure 1: Real GDP growth, GINI and KOF Indices, Ukraine 1998-2016
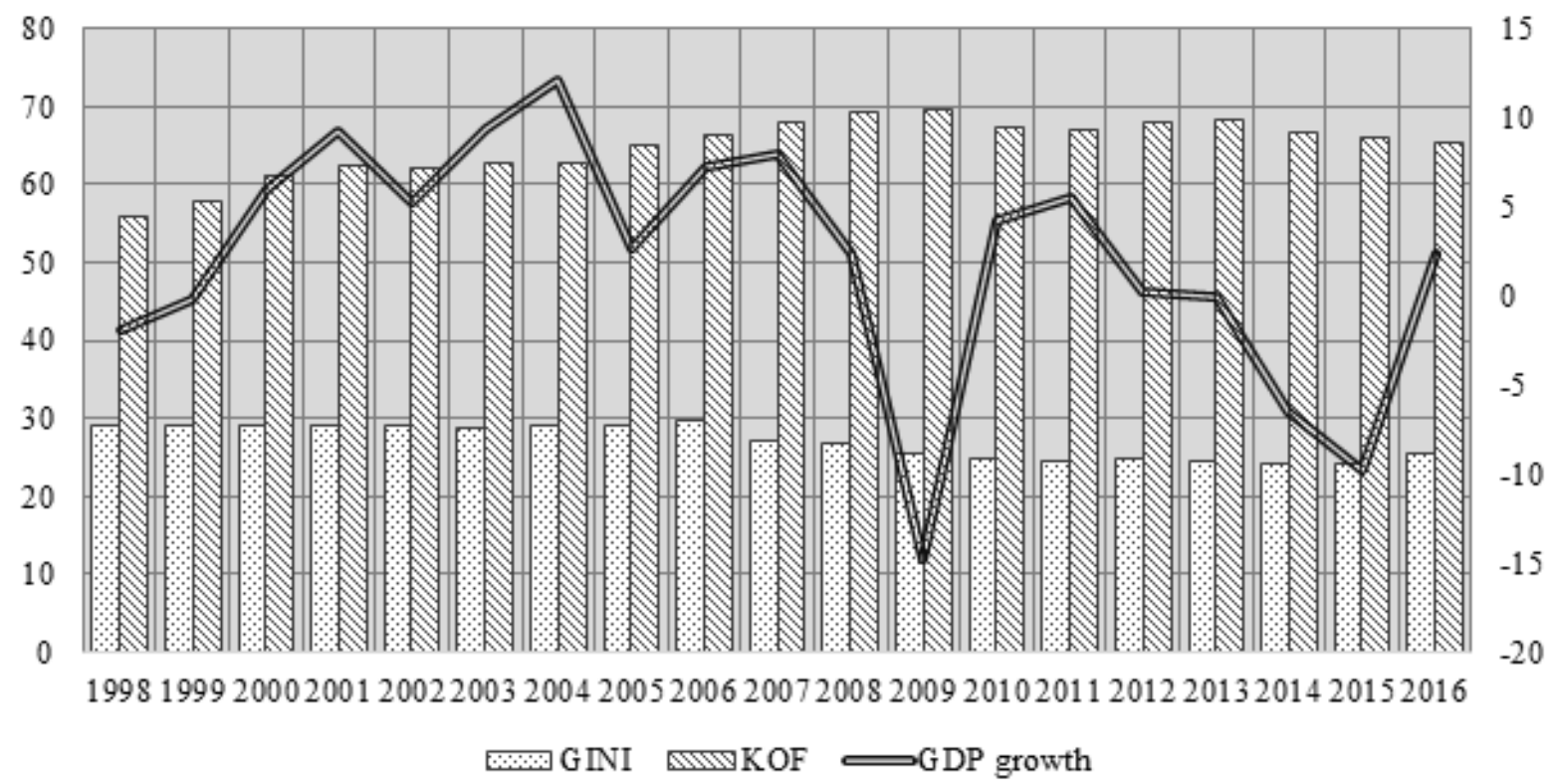

Source: Authors' Calculations based on World Bank open data (http://data.worldbank.org/) and KOF Swiss Economic Institute (http://globalization.kof.ethz.ch/)

As for the economic growth indicator, its correlation or causality with the other variables is not so obvious from figure, when considering GDP in other forms the figures shows a similar trend. 


\subsection{The Impact of Economic Growth on Income Inequality}

In the preliminary analysis of the data of strict dependence of Kuznets for the considered sample it was not found out. At the same time, the linear correlation coefficient of the GINI and GDP for Ukraine was -0.84 , which indicates a significant negative relationship between the level of development of the economy and the degree of differentiation of household incomes.

Results of testing for the presence of a unit root using Augmented Dickey-Fuller test (ADF) allowed it possible to conclude that the time series of the indicators under consideration are nonstationary and integrated order one. The basic equation, from which the analysis of mutual influence begins, establishes the possibility of the presence of cointegration between the investigated indicators and has the form:

$$
\begin{aligned}
& G D P=15916-319.7 G I N L R^{2}=0.702, D W=0.559 \\
& (P) \quad(0.00) \quad(0.00)
\end{aligned}
$$

where $\quad G D P$ is the gross domestic product per capita based on purchasing power parity GINI is Gini Index, which is a statistical measure of income distribution (the rate of income inequality)

$R^{2}$ is the coefficient of determination (R-squared)

$D W$ is the Durbin-Watson statistic, which usually used to detect the presence of autocorrelation at first lag in the residuals of regression model. Also DW can be used in test for cointegration. The null hypothesis for the test is that the residuals form a nonstationary random walk, whereas the alternative hypothesis is that the residuals form a stationary $\mathrm{AR}(1)$ process.

$P$ in brackets is $\mathrm{P}$-value for parameters and tests the null hypothesis that the coefficient is equal to zero (not statistically significant). A low p-value $(<0.01)$ indicates that we can reject the null hypothesis.

The results of the verification of rule Co-Integrating Regression Durbin-Watson (CRDW) and ADF-test confirm the hypothesis of stationarity of random error term or residuals of the model (1), therefore, it is a cointegration model in explicit form. For confirmation we used: from Eq. $4 \mathrm{DW}=0.559>\mathrm{d}_{0.05}=0.386$, where $\mathrm{d}_{0.05}-$ critical value of CRDW, and the results of ADF-test for Eq. 4 residuals $-\mathrm{P}_{\mathrm{ADF}}=0.013 \Rightarrow$ at a $2 \%$ level of significance we reject null hypothesis, the residuals does not have a unit root and are stationary (but at an alpha level of 0.01 residuals are non-stationary). At the same time, experiments with models have shown that the actualization of data leads to a decrease in the value of statistics DW and to an increase in the P-value of the ADF-test, which leads to the conclusion that there is no cointegration.

Tab. 1 presents results of the bounds test of a nonlinear autoregressive distributed lags (NARDL) model (1). Based on the estimates of the models described above, it can be concluded that at a $1 \%$ level of significance, the component reflecting the positive dynamics of the GINI index is cointegrated with the component, reflecting the negative dynamics of GDP, the remaining results of test at the considered level $\alpha$ indicate that there is no cointegration between the corresponding components. This confirms the negative relationship between indicators and in the case of economic slowdown should be expected stratification of the population by income to a greater extent. An interesting conclusion is that there is no link between the negative components of the indicators at any level of significance. Cointegration in the two remaining variants is observed only for certain values of the significance level: between the positive components of the indicators with an alpha level of $0.025(2.5 \%)$; between the component reflecting the negative dynamics of the GINI index and the component reflecting the positive dynamics GDP - at the $\alpha=0.05$ (5\%). 
Table 1: Bounds test results

\begin{tabular}{llllllll}
\hline GINI & GDP & $\mathrm{R}^{2}$ & $\mathrm{I}_{1} \%(0)$ & $\mathrm{I}_{1 \%}(1)$ & $\mathrm{F}_{\text {bounds test }}$ & Hypothesis & Cointegration \\
\hline positive & positive & 0.996 & 6.84 & 7.84 & 7.01 & inconclusive & No \\
positive & negative & 0.997 & 6.84 & 7.84 & 11.88 & $\mathrm{H}_{1}$ & Yes \\
negative & positive & 0.993 & 6.84 & 7.84 & 6.00 & $\mathrm{H}_{0}$ & No \\
negative & negative & 0.974 & 6.84 & 7.84 & 1.821 & $\mathrm{H}_{0}$ & No \\
\hline
\end{tabular}

Source: Own estimation (using EViews software)

In other words, in the analysis of these interdependencies for Ukraine, we find that the more likely one can expect the growing income inequality if the growth rate of the economy decreases, but with the same assumptions regarding the significance level - the positive economic growth will not lead to a decrease in population stratification by income.

\subsection{Testing Hypotheses II}

When testing the hypothesis II, it was decided to use the Granger causality test. Since the presence of a statistically significant correlation between all the indicators considered limits the use of multiple regression analysis methods. Tab. 2 presents results of Granger causality test, where $\mathrm{h}$ - number of tested lags.

Table 2: Pairwise Granger Causality Tests

\begin{tabular}{lllllll}
\hline Null Hypothesis & $\mathrm{h}=1$ & $\mathrm{~h}=2$ & $\mathrm{~h}=3$ & $\mathrm{~h}=4$ & $\mathrm{~h}=5$ & $\mathrm{~h}=6$ \\
\hline GINI does not Granger Cause KOF & 0.292 & 0.615 & 0.123 & 0.026 & 0.079 & 0.103 \\
KOF does not Granger Cause GINI & 0.013 & 0,047 & 0.068 & 0.261 & 0.537 & 0.435 \\
\hline Source: Own estimation (using EViews software) & & & & & &
\end{tabular}

At the $\alpha=5 \%$ level of significance the results of the Granger causality test allow us to confirm our original assumption about the presence of influence of KOF Globalization Index on GINI at $\mathrm{h}=1$ and $\mathrm{h}=2$, as well as at $\mathrm{h}=3$ with an alpha level of $0.07(7 \%)$. And then we can observe a change in the direction of the relationship. An empirical analysis of the data for the case of Ukraine showed that between the studied indicators GINI and KOF observed a linear relationship, with a certain increase in the variance of GINI with growth of KOF values. Based on the results of the conducted testing, we can talk about the presence of mutual influence between globalization and income inequality.

Accordingly, the results indicate that there is relationship between globalization and inequality in the long run (besides this is confirmed by cointegration testing). When the indicator of the scale of integration into the world space is rising - the income inequality inside the country is decreasing, the growth in income distribution inequality corresponds to a decrease in the degree of integration of the country into the world community. I.e., the statistical correlation coefficient between the indices KOF and GINI has a negative sign (-0.94), and in terms of interpretation, the relationship between the phenomena of globalization and the income inequality reduction is positive. Also the causality test revealed some cyclicality. There are periods, when globalization causes the income inequality but income inequality does not cause globalization, and vice versa.

\section{Discussion}

The results and findings could be a part of an information database used for decision-making within social and economic policies and, in this way, might be useful to decision-makers. The results obtained in some research directions and methods in empirical studies, such as 'between' and 'within' analysis approaches or asymmetry of effects, are of interest to state authorities in 
terms of interpreting current trends and interrelations, analysing social and economic policies and correcting the measures taken, taking into account the findings.

As already noted, interest in the issues being studied has resumed due to marked changes in many interrelations, known from economic theory, on the one hand, and the expected increase in problems related to poverty and the unequal distribution of income in society, on the other hand. The noted trends and forecasts of economic growth, given the presence of asymmetry effect, do not add optimism, but indicate the need for meticulous study of the issue to prepare relevant recommendations.

The International Monetary Fund (IMF) forecasts global GDP decline in the next few years (Fig. 2). Projections of economic growth in the CIS countries, and their neighbours, over the next five years are also more often characterized by rates of decline in economic growth, but, in any case, a return to previous growth trajectories is not foreseen in the near future. In most of the countries reviewed, the average predicted value of GDP growth in 2019-2022 is expected in some cases is almost two times lower than the same average value for the previous 20 years. This leads, according to the findings, that the income inequality reinforcing.

Figure 2: Dynamics of real GDP growth for the period 1998-2017 with IMF estimates between 2018 and 2022

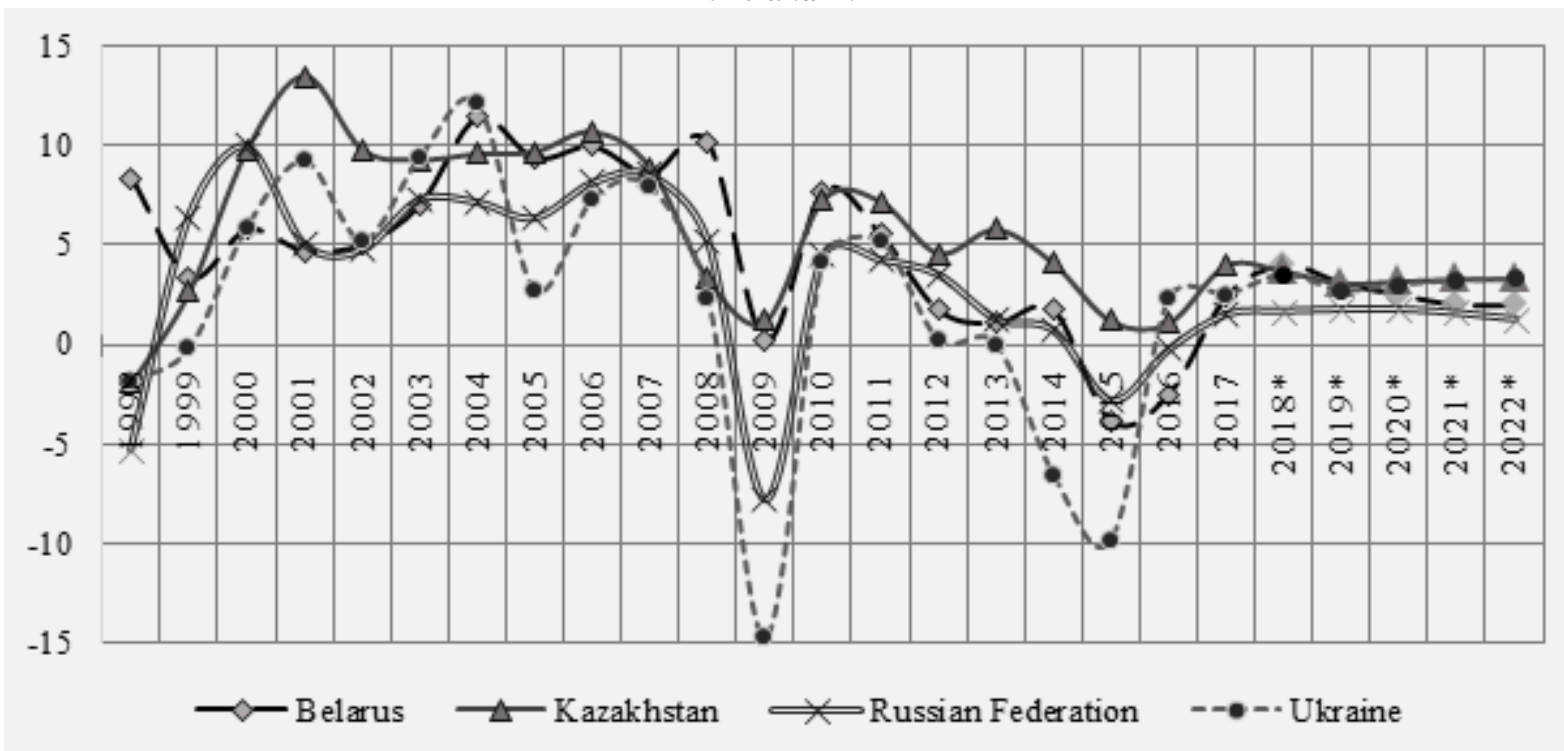

Source: Authors' Calculations based on World Bank open data (http://data.worldbank.org/) and International Monetary Fund data (http://imf.org/)

*: IMF estimates of real GDP growth

The decrease of inequality and poverty reduction strategies require for large scale public policies and actions which should not be focused only on growth and impact of globalization, but also but must take into account their effects and the consequences. As for globalization processes, in the opinion of the authors, every country can and must embrace economic globalization and get the new opportunities and benefits of economic globalization depending on each nation's economic structure.

Statistical and econometric methods in this context act as a means of analysing indicators of current processes, support of explanation and clarification of interrelationships for making more reasonable economic and political decisions. 


\section{Conclusion}

An analysis of the results of empirical studies of the relationship between economic growth and income inequality shows that the results largely depend on the choice of the model specification and the quality of the data used. The authors applied the bounds testing (ARDL) approach to cointegration to examine the long-run relationship between these variables. It can be said that the presence of significant inter-influence for these indicators was confirmed, which manifests itself to a greater extent in the case of the relationship between the positive component of the Gini index and the component, that reflects the negative dynamics GDP. From the authors' point of view, hidden cointegration explains some of the studies in which conflicting results were obtained regarding the tested relationship.

Also in the study, the authors tested the causal relationship between the processes of globalization and income inequality. Globalization is measured by the KOF globalization index. By the Granger causality test and through the correlation coefficients have been validated alleged links for both phenomena.

The improvement of economic and mathematical methods and models allows us to refine the already obtained results of empirical studies of interdependencies and to obtain new results. But in the opinion of the authors, more in-depth studies in this area also require the development of schemes of action for the formation a list of economic policy measures using the identified relationships, depending on the goals the government. As for the use of econometric methods, it's of authors' interests to study the asymmetries of effects using panel data models, and also the possibility of using global vector autoregressive model (GVAR) to analyse the problem in two directions: 'between' and 'within'.

\section{References}

Adams, S. (2007). Globalization and Income Inequality: Implications for Intellectual Property Rights. Journal of Policy Modelling, 30, 725-735.

Ahluwalia, M.S. (1976). Inequality, Poverty and Development. Journal of Development Economics, 3, 307-342.

Alderson, A. \& Nielsen F. (2002). Globalization and the Great U-Turn: Income Inequality Trends in 16 OECD Countries. American Journal of Sociology, 107(5), 1244-1299.

Alesina, A. \& Rodrik, D. (1994). Distributive Politics and Economic Growth. The Quarterly Journal of Economics, 109(2), 465-490.

Alesina, A. \& Perotti, R. (1996). Income Distribution, Political Instability, and Investment. European Economic Review, 40(6), 1203-1228.

Barro, R.J. (2000). Inequality and Growth in a Panel of Countries. Journal of Economic Growth, 5(1), 5-32.

Birdsall, N., Ross, D. \& Sabot R. (1995). Inequality and Growth Reconsidered: Lessons from East Asia. The World Bank Economics Review, 9(3), 477-508.

Bourguignon, F. (2016). The Globalization of Inequality. Princeton and Oxford: Princeton University Press.

Bourguignon, F. (2018). World Changes in Inequality: An Overview of Facts, Causes, Consequences, and Policies. CESifo Economic Studies, 64(3), 345-370.

Butkus, M., Maciulyte-Sniukiene, A. \& Matuzeviciute, K. (2017). Globalization, Development and Economic Growth: The Case of EU Member States. Globalization and its Socio-Economic Consequences 17th International Scientific Conference Proceedings. Rajecke Teplice, Slovak Republic, 240-247.

Deininger, K. \& Squire, L. (1998). New Ways of Looking at Old Issues: Inequality and Growth. Journal of Development Economics, 57(2), 259-287.

Engle, R.F. \& Granger, C.W.J. (1987). Co-Integration and Error Correction: Representation, Estimation, and Testing. Econometrica, 55, 251-276.

Figini, P. (1999). Inequality and Growth Revisited. Trinity College Economic Papers 99/2.

Forbes, K. (2000). A Reassessment of the Relationship between Inequality and Growth. American Economic Review, 90(4), 869-887.

Granger, C.W.J. (1988). Some Recent Developments in the Concept of Causality. Journal of Econometrics, 39 , 199-211. 
Granger, C.W.J. \& Yoon, G. (2002). Hidden Cointegration. Economic Working Paper Series, No. 539384, Department of Economics, University of California at San Diego.

Kaldor, N. (1956) Alternative Theories of Distribution. Review of Economic Studies, 23(2), 83-100.

Keane, M.P. \& Prasad, E.S. (2001). Poland: Inequality, Transfers and Growth in Transition. Finance and Development, 38(1), 50-53.

KOF Swiss Economic Institute (2017). KOF Globalization Index. [Online]. Available at: http://globalization.kof.ethz.ch

Kuznets, S. (1955). Economic Growth and Income Inequality. The American Economic Review, 45, 1-28.

Madsen, J. B., Islam, Md. R. \& Doucouliagos, H. (2018). Inequality, Financial Development and Economic Growth in the OECD, 1870-2011. European Economic Review, 101(C), 605-624.

Michalek, A. \& Vybostok, J. (2018). Economic Growth, Inequalities and Poverty in Slovakia from 2005 to 2015 (the Analysis of Relations and Contexts at a Regional Level). European Spatial Research and Policy, 25, 5574.

Milanovic, B. (2016). Global Inequality: A New Approach for the Age of Globalization. Cambridge: Harvard University Press.

Oshima, H.T. (1962). The International Comparison of Size Distribution of Family Incomes with Special Reference to Asia. Review of Economics and Statistics, 44, 439-445.

Paukert, F. (1973). Income Distribution of Different Levels of Development: A Survey of Evidence. International Labour Review, 108(2-3), 97-125.

Persson, T. \& Tabellini, G. (1994). Is Inequality Harmful for Growth? American Economic Review, 84(3), 600621.

Ravallion, M. (1997). What Can New Survey Data Tell Us About Recent Changes in Distribution and Poverty. World Bank Research Observer, 11(2), 357-382.

Sonin, C. (2000). Inequality, property rights, and economic growth in transition economies: Theory and Russian evidence, EERC Working Paper Series 2K/02.

Rodrik, D. (1999). Where did All the Growth Go? External Shocks, Social Conflict and Growth Collapses. Journal of Economic Growth, 4(4), 385-412.

Wei, S. \& Y. Wu. (2001). Globalization and Inequality: Evidence from Within China. NBER Working Paper 8611. National Bureau of Economic Research, Inc.

Zhou, L., Biswas, B., Bowles, T. \& Saunders, PJ. (2011). Impact of Globalization on Income Distribution Inequality in 60 Countries. Global Economy Journal, 11(1), 1-18. 